\title{
Truth, Lies, and O-rings Inside the Space Shuttle Challenger Disaster
}

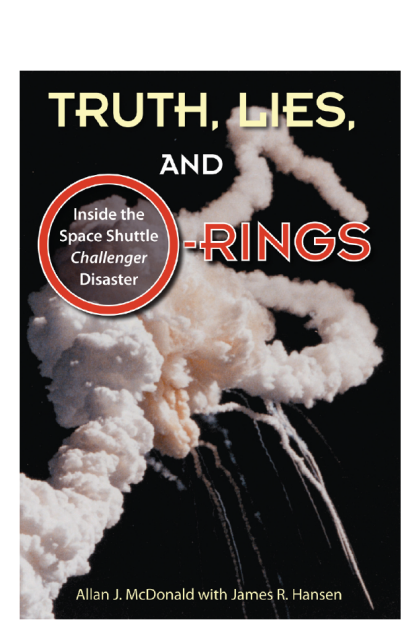

\author{
Allan McDonald \\ Sponsored by AIAA \& IEEE \\ Thursday, \\ April 8, 7:00 p.m. \\ LL125/126, Lind Lecture Hall \\ 1551 Edvalson St, Ogden, Utah \\ Weber State University
}

\section{Allan McDonald will discuss his book, Truth, Lies, and O-rings: Inside the Shuttle Challenger Disaster. Books will be available and a book signing will follow the talk. The presentation is open to the public.}

\footnotetext{
About Allan McDonald:

Allan J. McDonald received a B.S. in Chemical Engineering from Montana State University in 1959 and an M.S. in Engineering Administration from the University of Utah in 1967; retiring in 2001 from ATK Thiokol Propulsion after a 42-year career with the company. He was the Director of the Space Shuttle Solid Rocket Motor Project at the time of the Challenger accident and led the redesign of the solid rocket motors as Vice President of Engineering for Space Operations. He has several patents related to rocket propulsion, published over 80 technical papers that have been presented in national and international conferences, and received numerous professional awards.
} 